\title{
Evidence That Excitatory Amino Acid Receptors within the Temporomandibular Joint Region Are Involved in the Reflex Activation of the Jaw Muscles
}

\author{
Brian E. Cairns, Barry J. Sessle, and James W. Hu \\ Department of Oral Physiology, Faculty of Dentistry, The University of Toronto, Toronto, Ontario M5G 1G6, Canada
}

\begin{abstract}
We have previously shown that injection of the inflammatory irritant and small-fiber excitant mustard oil (MO) into the temporomandibular joint (TMJ) region can reflexively induce a prolonged increase in the activity of both digastric and masseter muscles in rats. It is possible that peripheral excitatory amino acid (EAA) receptors play a role in this effect, because MOevoked increases in jaw muscle activity are attenuated by preapplication of the noncompetitive NMDA receptor antagonist MK-801 into the TMJ region. In the present study the EAA receptor agonists glutamate, NMDA, kainate, and AMPA were applied locally to the TMJ region. Jaw muscle responses similar to those evoked by $\mathrm{MO}$ application to the TMJ region were achieved with glutamate, NMDA, AMPA, and kainate. Repeated application of glutamate, NMDA, or AMPA at intervals of 30 min evoked responses in the ipsilateral jaw muscles that were of
\end{abstract}

comparable magnitude. Co-application of the NMDA receptor antagonist DL-2-amino-5-phosphonovalerate $(0.5 \mu \mathrm{mol})$ significantly reduced the magnitude of the glutamate- and NMDAevoked ipsilateral jaw muscle responses without affecting responses evoked by AMPA. In contrast, co-application of the non-NMDA receptor antagonist 6-cyano-7-nitroquinoxaline2,3-dione (1 nmol) significantly reduced the magnitude of the glutamate- and AMPA-evoked ipsilateral jaw muscle responses without affecting responses evoked by NMDA. This evidence suggests that both NMDA and non-NMDA EAA receptor types are located within the TMJ region and may contribute to jaw muscle activity that can be reflexively evoked from the TMJ region.

Key words: digastric muscle; excitatory amino acids; masseter muscle; pain; temporomandibular joint; trigeminal
Recently, it has been demonstrated that excitatory amino acid (EAA) receptors are present not only on dorsal root and trigeminal ganglion neurons (Sato et al., 1993; Tachibana et al., 1994; Pelkey and Marshall, 1995; Sahara et al., 1997) but also on the peripheral ends of small-diameter primary afferents (Carlton et al., 1995) as well as non-neural peripheral tissues (Erdo, 1991). Whether such receptors have a functional role in translating the features of nociceptive stimuli into neural codes has yet to be determined. However, it has been suggested that activation of these receptors by local application (e.g., subdermal) of glutamate and selective EAA receptor agonists may result in peripheral sensitization (Carlton et al., 1995; Jackson et al., 1995; Z hou et al., 1996; Davidson et al., 1997; Lawand et al., 1997) or even elicit nociceptive responses (Ault and Hildebrand, 1993a,b). Furthermore, it appears that part of the nociceptive mechanisms underlying the actions of inflammatory irritants and algesic chemicals, such as mustard oil (MO), may result from the activation of peripheral EAA receptors (Yu et al., 1996).

We have presented evidence that peripheral NMDA receptors may play a role in mediating increases in jaw muscle activity resulting from application of inflammatory irritants and algesic chemicals to the temporomandibular joint (TMJ) region (Yu et al., 1996). Specifically, local application of the inflammatory irritant $\mathrm{MO}$ to the rat TMJ region was shown to increase jaw

\footnotetext{
Received April 8, 1998; revised June 26, 1998; accepted July 21, 1998.

This research was supported by National Institutes of Health Grant DE11995. We thank K. MacLeod for electronic services.

Correspondence should be addressed to Dr. James W. Hu, Faculty of Dentistry, The University of Toronto, 124 Edward Street, Toronto, Ontario M5G 1G6, Canada.

Copyright (C) 1998 Society for Neuroscience $\quad 0270-6474 / 98 / 188056-09 \$ 05.00 / 0$
}

electromyographic activity (Yu et al., 1995). However, increases in jaw muscle activity as a result of MO application to the TMJ region were attenuated by preapplication of the noncompetitive NMDA receptor antagonist MK-801 into the TMJ. This result suggests that part of the action of MO might be mediated through the activation of peripheral NMDA receptors.

The present study was undertaken to investigate whether both NMDA and non-NMDA peripheral EAA receptors are located within the TMJ region. Glutamate and the selective EAA receptor agonists NMDA, kainate, and AMPA were applied to the TMJ region in an attempt to evoke reflex jaw muscle activity. The results show that when applied to the TMJ region in adequate doses, these EAA agonists can increase jaw muscle activity in a manner analogous to other algesic chemicals, such as potassium chloride, hypertonic saline, and bradykinin, as well as MO (Broton and Sessle, 1988; Yu et al., 1995). EAA receptor agonistevoked jaw muscle activity can be reduced by antagonists selective for both NMDA and non-NMDA receptors. These results provide evidence in support of the hypothesis that functional EAA receptors are located within the TMJ region.

A portion of these data has been previously presented in abstract form (Cairns et al., 1997).

\section{MATERIALS AND METHODS}

A total of 137 male Sprague Dawley rats (250-450 gm) were prepared for acute recording of jaw muscle electromyographic (EMG) activity as previously described (Hu et al., 1993; Yu et al., 1994, 1995, 1996). Briefly, under surgical anesthesia $\left(\mathrm{O}_{2}, 0.3-0.4 \mathrm{l} / \mathrm{min} ; \mathrm{N}_{2} \mathrm{O}, 0.6-0.7 \mathrm{l} / \mathrm{min}\right.$; halothane, $1.5-2 \%$ ) a tracheal cannula was inserted, and the left femoral vein was cannulated. Bipolar electrodes were fashioned out of 36 gauge Teflon-coated single-strand stainless steel wire and inserted bilaterally into the digastric and masseter muscles. The rat's head was placed in a 
stereotaxic frame, the skin over the dorsal surface of the skull was reflected, and two screws were inserted into the parietal bone. These screws were attached to a vertical support bar with dental acrylic to facilitate access to the TMJ region and thereby allowed the ear bars to be removed. On removal of the ear bars, the needle tip of a catheter, consisting of a 27 gauge needle connected by polyethylene tubing to a Hamilton syringe $(50 \mu \mathrm{l})$, was carefully inserted into the TMJ region and used for drug applications.

In some experiments, an incision was made in the skin over the neck to expose the brainstem and upper cervical spinal cord. A laminectomy was performed on the $\mathrm{C} 1$ vertebra, and the dura overlying the brainstem and cervical spinal cord was removed. A $5 \mu$ l Hamilton syringe was placed in contact with the brainstem and used to apply either lidocaine or normal saline onto it.

On completion of the surgery, the anesthetic level was slowly reduced until noxious pinch of the hindpaw toes produced a slight limb withdrawal reflex. This was regularly achieved at halothane concentrations of $0.7-1.0 \%$. The animal was then maintained at this level of anesthesia for the duration of the experiment. Heart rate and core body temperature were monitored throughout the experiment and maintained within normal physiological limits. All surgeries and procedures were approved by the University of Toronto Animal Care Committee in accordance with the regulations of the Ontario Animal Research Act (Canada).

Drug solutions. The following drugs were used in the present study: the inflammatory irritant and small-fiber excitant MO (allylisothiocyanate $20 \%$ in mineral oil; BDH, Poole, Dorset, UK); the EAA receptor agonists glutamic acid, NMDA, kainic acid, and AMPA; the EAA receptor antagonists DL-2-amino-5-phosphonovalerate (APV) and 6-cyano-7-nitroquinoxaline-2, 3-dione (CNQX); and lidocaine $\mathrm{HCl} 1 \%$ (Xylocaine, Astra). EAA receptor agonists and antagonists were acquired from Research Biochemicals International (Natick, MA). All EAA receptor agonists and antagonists were dissolved in isotonic saline, and the resulting solutions were adjusted to a $\mathrm{pH}$ of $\sim 7$. MO (total volume, $20 \mu \mathrm{l}$ ) or EAA receptor agonists and antagonists (total volume, $10 \mu \mathrm{l}$ ) were injected into the TMJ region via the needle and catheter (see above). We have previously demonstrated that injection of mineral oil or isotonic saline into the TMJ region does not evoke any significant change in EMG activity in the digastric or masseter muscles (Yu et al., 1995, 1996).

Stimulation and recording techniques. To decrease the total number of rats used in the present study, applications of drugs to the TMJ region were made bilaterally. Glutamate injections into the left and right TMJ regions were separated by $60 \mathrm{~min}$ to avoid any potential modulatory influence of the first series of injections on the jaw muscle activity evoked by the second series of injections (Bakke et al., 1998). Baseline EMG activity was observed for $10 \mathrm{~min}$ before TMJ application. In initial experiments, EAA receptor agonists (glutamate, NMDA, kainate, and AMPA) and MO were then slowly injected once into the TMJ region over $\approx 5 \mathrm{sec}$, and the resulting changes in EMG activity were recorded for 30 min after injection.

In later experiments, repeated applications of EAA receptor agonists and MO were made to the TMJ region. Up to three applications of the same dose of each EAA receptor agonist (NMDA, AMPA, or kainate, $0.5 \mu \mathrm{mol}$; glutamate, $2.5 \mu \mathrm{mol})$ to the TMJ region were made with intervals of $30 \mathrm{~min}$ between each application. In some experiments, the EAA receptor antagonists APV $(0.5 \mu \mathrm{mol})$ and CNQX (1 or $20 \mathrm{nmol})$ were co-applied with the EAA receptor agonists for the second injection. In another series of experiments lidocaine $(1 \%, 2 \mu \mathrm{l})$ or normal saline $(2$ $\mu \mathrm{l})$ was applied topically to the brainstem ( $1 \mathrm{~mm}$ lateral and $4 \mathrm{~mm}$ caudal to the obex) 1 min before the second injection of glutamate into the TMJ region.

Implanted bipolar electrodes were used to record EMG activity from both ipsilateral and contralateral digastric and masseter muscles (Hu et al., 1993; Yu et al., 1995). EMG activity was amplified (gain, 500×; bandwidth, 30-1000 Hz) and fed into a computer equipped with a CED 1401 Plus board and analysis software (Spike 2; Cambridge Electronics). Recorded EMG activity was stored electronically and analyzed offline.

Data analysis and statistics. Recorded EMG data were rectified off-line, and EMG area bins (microvolts per minute) were calculated. Baseline EMG activity was calculated as a mean of EMG area bins recorded over the first $10 \mathrm{~min}$ before injection of agents into the TMJ region. Relative EMG activity was calculated by normalizing EMG area bins to the baseline EMG activity and was used to illustrate the results of individual experiments. Agents applied to the TMJ region were considered to have evoked jaw muscle activity if the value of the first EMG bin after TMJ application was $>2$ SD above the baseline (Yu et al., 1995). The value of the baseline plus 2 SD was chosen as a signal to noise limit because it represents an approximation of the $95 \%$ confidence interval for the mean baseline activity. The relative area under the EMG response curve (AUC) was calculated by summing the value of the first and all subsequent EMG area bins $>2$ SDs above baseline EMG activity and defined as the overall response.

Significant differences in the relative AUC for multiple applications of glutamate or other EAA agonists were determined with a repeated measures ANOVA on ranks $(p<0.05)$. Significant differences in the relative AUC for paired applications of glutamate or other EAA agonists were determined with a paired Student's $t$ test or Wilcoxon signed rank test $(p<0.05)$. All values are expressed as a mean $\pm \mathrm{SE}$.

Terminal procedures. At the end of each experiment, rats were killed with T61 (Hoechst). In some rats treated with MO or glutamate, Evans blue dye $(6 \mathrm{mg} / \mathrm{kg})$ was injected into the femoral vein $10 \mathrm{~min}$ before killing. After killing the rat, the tissue surrounding the TMJ region was gently dissected out of the way, and a visual examination of the TMJ and surrounding tissues was made. The presence of any blue staining was taken as an indication of plasma protein extravasation into the TMJ region (Haas et al., 1992; Yu et al., 1995).

\section{RESULTS}

\section{Dose-response relationship}

Application of MO to the TMJ region bilaterally in three rats activated both the ipsilateral and contralateral jaw muscles with a characteristic time course (see example in Fig. 1). The latency to onset for MO-evoked EMG activity ranged from 3 to $8 \mathrm{sec}$ (mean, $4.8 \pm 0.4 \mathrm{sec}$ ). The mean AUCs were similar to those described previously (Hu et al., 1993).

In Figure 1, jaw muscle EMG responses evoked by the application of the EAA receptor agonists glutamate, NMDA, kainate, and AMPA are compared with those evoked by MO. The EMG curves chosen reflect the dose at which EAA receptor agonist and MO-evoked activity in the ipsilateral digastric muscle were found to be equivalent (Fig. 2). The latency to onset of jaw muscle activity for NMDA (mean, $4.2 \pm 0.6 \mathrm{sec}$ ) and AMPA (mean, $4.3 \pm 0.4 \mathrm{sec})$ was similar to that for MO $(p>0.05$, Student's $t$ test). However, the latency to onset of jaw muscle activity evoked by glutamate (mean, $9.3 \pm 0.8 \mathrm{sec}$ ) and kainate (mean, $12 \pm 0.8$ sec) was significantly longer than that evoked by $\mathrm{MO}(p<0.05$, Student's $t$ test). Note that TMJ application of MO was generally more effective than TMJ application of any of the EAA receptor agonists in activating the contralateral jaw muscles. In fact, TMJ application of MO evoked activity in the contralateral masseter muscle with an incidence of $83 \%$, compared with only $17 \%$ for glutamate, $50 \%$ for NMDA, $33 \%$ for AMPA, and 17\% for kainate. In the contralateral digastric muscle, application of MO evoked activity with an incidence of $100 \%$, compared with $33 \%$ for glutamate, $83 \%$ for NMDA, 50\% for AMPA, and 67\% for kainate.

Increasing doses of glutamate (doses: $0.1,0.25,0.5,1.0,2.5$, and $5 \mu \mathrm{mol}$ ) or the specific EAA receptor agonists NMDA, AMPA, and kainate (doses: $0.1,0.25,0.5$, and $1.0 \mu \mathrm{mol}$ ) were applied to the TMJ region ( $n=65$ rats) in an attempt to evoke activity in either the ipsilateral or contralateral jaw muscles in a manner analogous to that of MO. Dose-response curves constructed for the ipsilateral and contralateral jaw muscles are shown in Figures 2 and 3. The curves reveal a sharp dose-response relationship for activation of the ipsilateral digastric muscle. For all the EAA receptor agonists tested, doses of $\leq 0.1 \mu \mathrm{mol}$ were ineffective in activating either the ipsilateral or contralateral digastric muscle. At any given dose, however, there was a considerable interanimal variation in the magnitude of individual digastric muscle responses, as revealed by the large SE bars.

The dose-response relationship of the contralateral digastric 


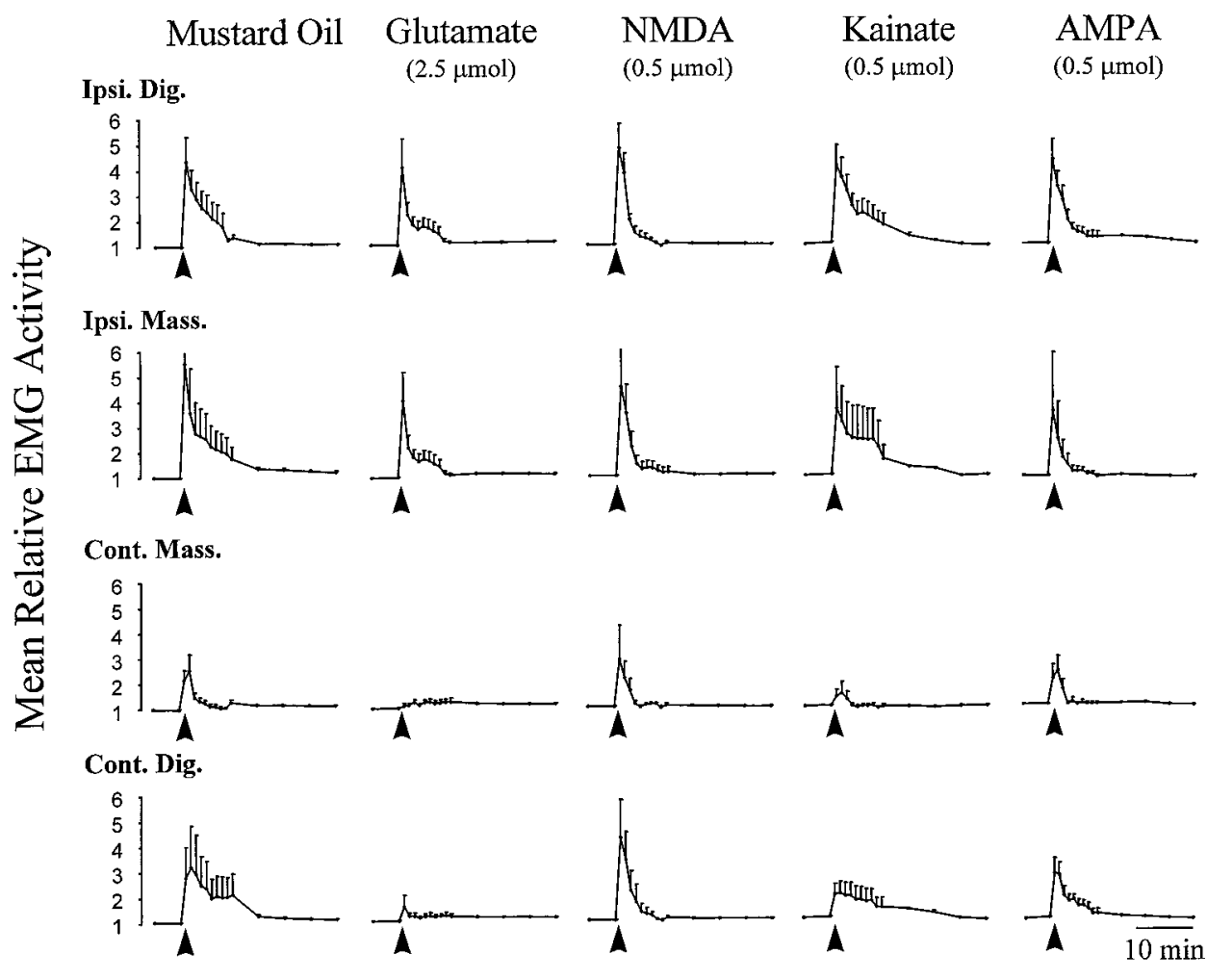

Figure 1. Comparison of typical responses evoked in the jaw muscles as a result of local application of MO and EAA receptor agonists to the TMJ region. Data points indicate the mean EMG $(n=6)$ relative to preinjection baseline EMG activity. Error bars indicate SE. Solid arrows below each curve indicate the time of application. Application of MO to the TMJ region resulted in a characteristic increase in the electromyographic activity of jaw muscles both ipsilateral and contralateral to the injection site (Yu et al., 1995, 1996). Application of the EAAs to the TMJ region evoked activity in the ipsilateral jaw muscles that was similar to that evoked by MO. The above data suggest that activation of either NMDA or non-NMDA EAA receptors within the TMJ region may provide sufficient stimulation to evoke lateral digastric muscle; Ipsi. Mass., ipsilateral masseter muscle; Cont. Mass., contralateral masseter Muscle; Cont. Dig., contralateral digastric muscle. reflex jaw muscle activity. Ipsi. Dig., Ipsi-

$\begin{array}{ccccc}\text { Mustard Oil } & \begin{array}{c}\text { Glutamate } \\ (2.5 \mu \mathrm{mol})\end{array} & \begin{array}{c}\text { NMDA } \\ (0.5 \mu \mathrm{mol})\end{array} & \begin{array}{c}\text { Kainate } \\ (0.5 \mu \mathrm{mol})\end{array} & \begin{array}{c}\text { AMPA } \\ (0.5 \mu \mathrm{mol})\end{array} \\ \text { Ipsi. Dig. } & & & \end{array}$$$
\begin{aligned}
& 5 \\
& 4 \\
& 3 \\
& 2
\end{aligned}
$$

11

psi. Mass.

muscle to application EAAs to the TMJ region differed from that of the ipsilateral digastric muscle in that the maximal responses were not similar to those evoked by MO. The dose-response curves constructed for the ipsilateral and contralateral masseter muscles were similar to those of the contralateral digastric muscle (Fig. 3). Other than at the highest dose of glutamate $(5 \mu \mathrm{mol})$, application of EAA receptor agonists to the TMJ region evoked activity in the ipsilateral and contralateral masseter muscles that was less than that evoked by MO. This suggests that EAA receptor agonist application to the TMJ region is not as effective as MO at evoking activity in these jaw muscles.

To rule out the possibility that some of the jaw muscle activity evoked by application of EAAs to the TMJ region was attributable to a systemic action of the EAA receptor agonists, the highest doses of glutamate ( $5 \mu \mathrm{mol} ; n=2$ rats), NMDA (0.5 $\mu \mathrm{mol} ; n=2$ rats $)$, AMPA $(0.5 \mu \mathrm{mol} ; n=2$ rats $)$, and kainate $(0.5$ $\mu \mathrm{mol} ; n=2$ rats) used in the present study were mixed in $0.1 \mathrm{ml}$ of normal saline and given intravenously into the femoral vein. None of the EAA receptor agonists evoked jaw muscle activity when given systemically at these doses.

\section{Repeated application of EAA receptor agonists}

It has been suggested that peripheral EAA receptors may undergo desensitization during an extended exposure to EAA receptor agonists (Agrawal and Evans, 1986; Huettner, 1990). To test whether peripheral EAA receptors in the TMJ region undergo such a desensitization process, jaw muscle activity was observed during repeated application of EAA agonists at varying time intervals ( $n=12$ rats). In preliminary experiments, it was determined that if the interval between TMJ application of glutamate was $<30 \mathrm{~min}$, there was a decrease in the magnitude of the second and subsequent EMG responses when compared with the first response. At intervals of $30 \mathrm{~min}$, it was possible to evoke responses in the ipsilateral digastric and masseter muscles that were of equal magnitude (Fig. 4). It was subsequently found that NMDA and AMPA also evoked responses of similar magnitude over three repeated applications at $30 \mathrm{~min}$ intervals (Fig. 4). However, kainate responses significantly decreased with repeated application even at this $30 \mathrm{~min}$ interval $(p<0.05$, repeated measures ANOVA). Repeated applications of MO to the TMJ region were never effective in evoking second responses in either the digastric or masseter muscles (data not shown).

The reproducibility of EMG responses with glutamate, NMDA, and AMPA made it possible to design paired experiments to examine the interaction between EAA receptor agonists and the NMDA receptor antagonist APV ( $n=12$ rats) or the nonNMDA receptor antagonist CNQX ( $n=12$ rats). In the ipsilateral digastric muscle, co-application of APV $(0.5 \mu \mathrm{mol})$ significantly reduced the EMG responses evoked by glutamate and NMDA, without significantly affecting the AMPA-evoked EMG responses (Table 1, Fig. 5). In the ipsilateral masseter muscle, co-application of APV reduced the glutamate- and NMDAevoked responses without significantly affecting the AMPAevoked responses (Table 1). This result suggests that the dose of APV used was selective for peripheral NMDA receptors located within the TMJ region.

\section{CNQX}

In the ipsilateral digastric muscle, co-application with CNQX (1 nmol) reduced the glutamate and AMPA-evoked EMG responses, without significantly affecting the NMDA-evoked EMG responses (Table 1, Fig. 6). In the ipsilateral masseter muscle, co-application of CNQX reduced the glutamate- and AMPAevoked EMG responses, also without significantly affecting the

\section{Effect of selective EAA receptor antagonists $A P V$}




\section{Digastric Muscle}

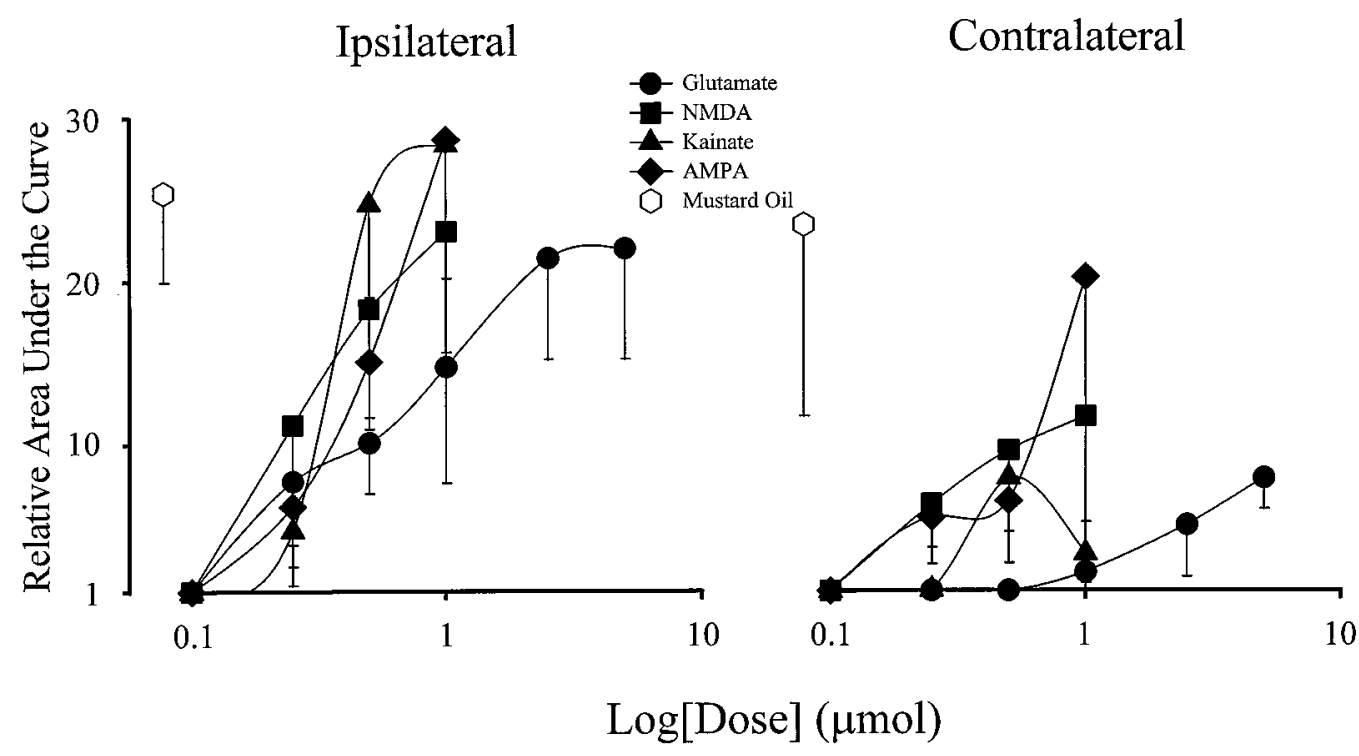

Figure 2. Dose-response relationship for evoked activity in the digastric muscles by application of EAA receptor agonists to the TMJ region. Each data point on the dose-response curves represents a mean value $(n=6)$. Error bars indicate SE. Note that responses of magnitude similar to those evoked by $\mathrm{MO}$ in the ipsilateral digastric were achieved with $0.5 \mu \mathrm{mol}$ doses of NMDA, AMPA, and kainate and $2.5 \mu$ mol doses of glutamate, respectively.

\section{Masseter Muscle}

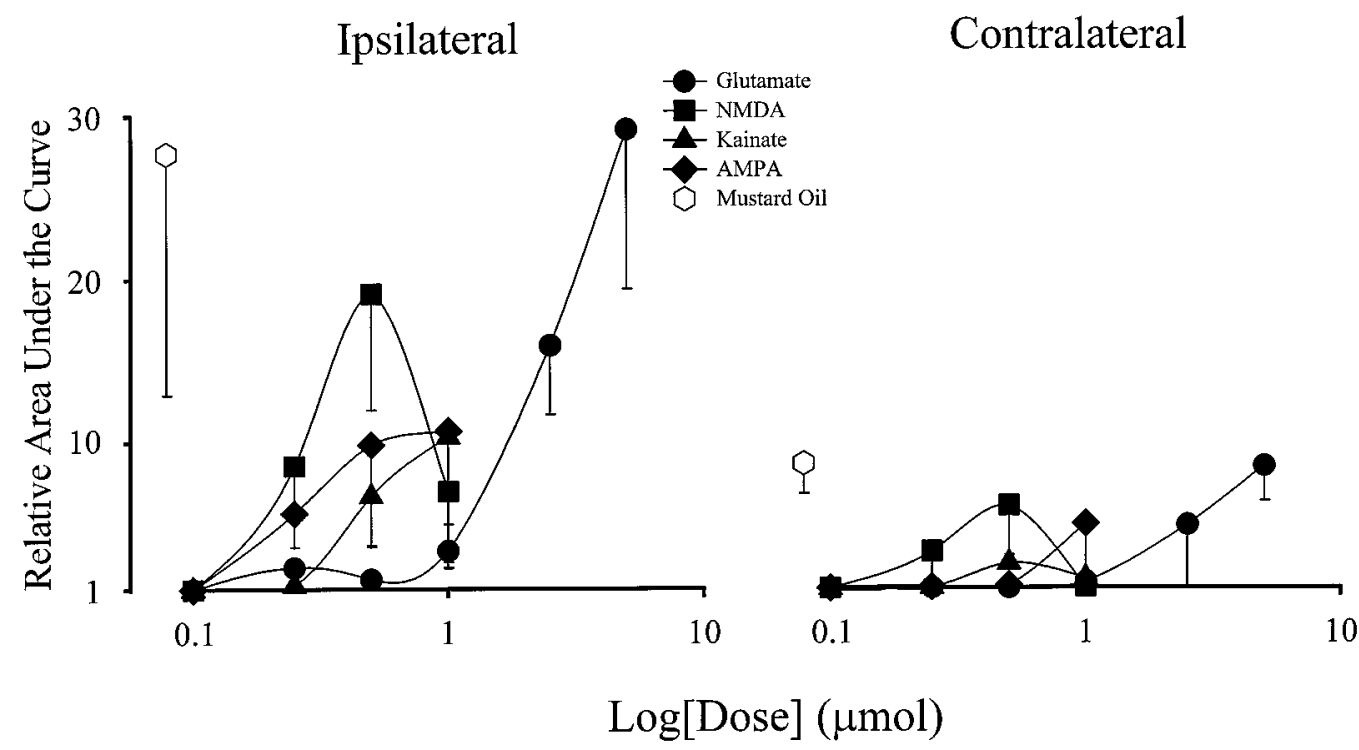

Figure 3. Dose-response relationship for evoked activity in the masseter muscles by application of EAA receptor agonists to the TMJ region. Each data point on the dose-response curves represents a mean value $(n=6)$. Error bars indicate SE. Note that responses of magnitude similar to those evoked by MO in the ipsilateral and contralateral masseter were only achieved for glutamate at a dose of $5.0 \mu \mathrm{mol}$, the highest dose applied for any of the EAA receptor agonists.

NMDA-evoked EMG responses (Table 1). This result suggests that the dose of CNQX used was selective for peripheral nonNMDA receptors located within the TMJ region.

There is evidence that at higher concentrations, CNQX can act as a noncompetitive antagonist of the NMDA receptor (Birch et al., 1989; Yamada et al., 1989; Hablitz and Sutor, 1990) (for review, see Collingridge and Lester, 1989). In an additional set of experiments ( $n=3$ rats), a higher dose of CNQX (20 nmol) was co-applied to the TMJ region with NMDA (Table 1, bottom), and it was found that this dose of CNQX significantly decreased the NMDA-evoked EMG responses in both the ipsilateral digastric and masseter muscles. 
Figure 4. Digastric muscle activity evoked by repeated applications of EAA receptor agonists to the TMJ region. $A$, Line plots illustrate the activity evoked in the ipsilateral digastric muscle by three applications (solid arrow) each of glutamate $(2.5 \mu \mathrm{mol})$, NMDA, AMPA, and kainate $(0.5 \mu \mathrm{mol})$ in four individual experiments. Relative EMG activity was calculated by normalizing each EMG area bin to the mean of baseline EMG activity before the first injection. $B$, Bar graphs indicate the mean $\pm \mathrm{SE}(n=6)$ for each of the three trials. Note that for glutamate, NMDA, and AMPA, repeated application evoked activity of equal magnitude when compared with the first response $(p>0.05$, repeated measures ANOVA). However, the magnitude of digastric muscle responses to repeated applications of kainate progressively decreased $(p<0.05$, repeated measures ANOVA), suggesting that a process of desensitization may be occurring.

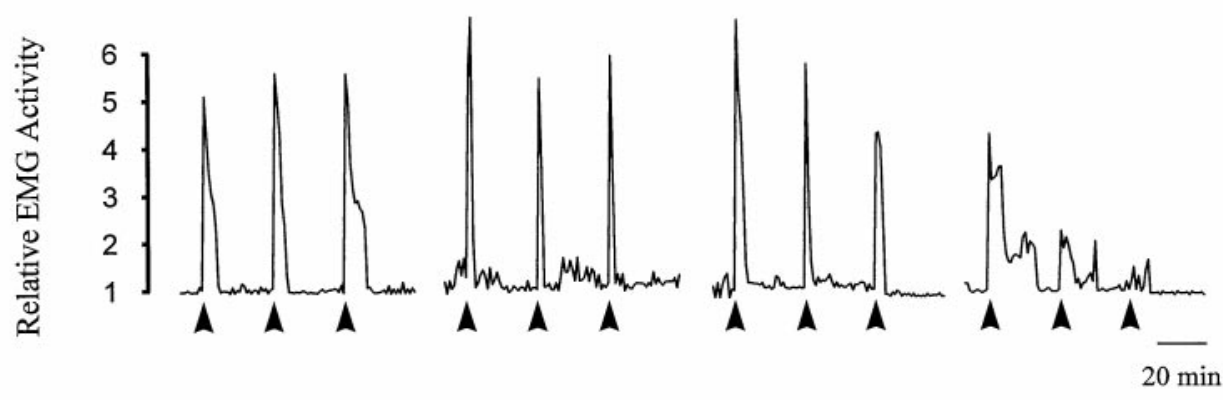

$\mathrm{B}$

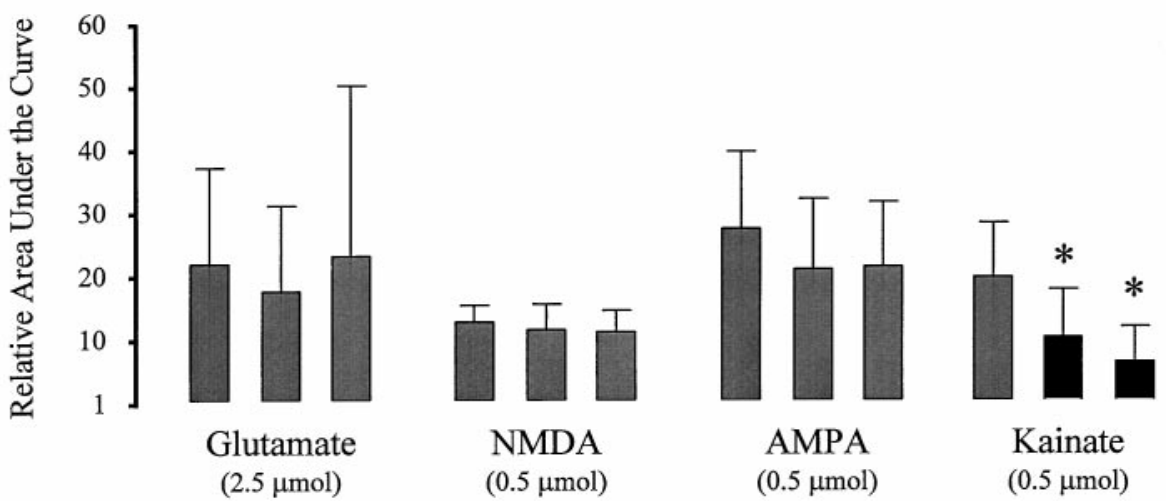

Table 1. Summary of data from paired experiments using EAA receptor antagonists

\begin{tabular}{lcc} 
& \multicolumn{2}{l}{ Area under the curve } \\
\cline { 2 - 3 } Antagonist & Digastric muscle & Masseter muscle \\
\hline Glutamate $(2.5 \mu \mathrm{mol})$ & $19.3 \pm 10$ & $25.8 \pm 9.7$ \\
Glutamate $(2.5 \mu \mathrm{mol})$ and APV $(0.5 \mu \mathrm{mol})$ & $\mathbf{9 . 1} \pm \mathbf{3 . 3}$ & $\mathbf{1 1 . 3} \pm \mathbf{6 . 1}$ \\
NMDA $(0.5 \mu \mathrm{mol})$ & $18.3 \pm 7.4$ & $20.2 \pm 6.8$ \\
NMDA $(0.5 \mu \mathrm{mol})$ and APV $(0.5 \mu \mathrm{mol})$ & $\mathbf{8 . 6} \pm \mathbf{4 . 8}$ & $15.9 \pm 4.5$ \\
AMPA $(0.5 \mu \mathrm{mol})$ & $36.4 \pm 20.0$ & $22.5 \pm 9.9$ \\
AMPA $(0.5 \mu \mathrm{mol})$ and APV $(0.5 \mu \mathrm{mol})$ & $34.0 \pm 14.8$ & $19.3 \pm 9.4$ \\
Glutamate $(2.5 \mu \mathrm{mol})$ & $44.5 \pm 12.9$ & $29.5 \pm 11.0$ \\
Glutamate $(2.5 \mu \mathrm{mol})$ and CNQX $(1 \mathrm{nmol})$ & $\mathbf{2 2 . 7} \pm \mathbf{9 . 6}$ & $\mathbf{2 0 . 8} \pm \mathbf{1 1 . 8}$ \\
NMDA $(0.5 \mu \mathrm{mol})$ & $30.4 \pm 6.4$ & $5.0 \pm 2.8$ \\
NMDA $(0.5 \mu \mathrm{mol})$ and CNQX $(1 \mathrm{nmol})$ & $27.6 \pm 8.7$ & $3.2 \pm 1.3$ \\
AMPA $(0.5 \mu \mathrm{mol})$ & $26.0 \pm 8.0$ & $26.2 \pm 8.3$ \\
AMPA $(0.5 \mu \mathrm{mol})$ and CNQX $(1 \mathrm{nmol})$ & $\mathbf{1 2 . 0} \pm \mathbf{9 . 0}$ & $11.7 \pm 8.5$ \\
NMDA $(0.5 \mu \mathrm{mol})$ & $26.8 \pm 7.2$ & $19.4 \pm 10.5$ \\
NMDA $(0.5 \mu \mathrm{mol})$ and CNQX $(20 \mathrm{nmol})$ & $\mathbf{7 . 9} \pm \mathbf{2 . 6}$ & $7.9 \pm \mathbf{5 . 8}$
\end{tabular}

Each mean \pm SE was calculated from the results of six experiments. Note that APV, a competitive NMDA receptor antagonist, decreased jaw muscle activity evoked by NMDA and glutamate, whereas CNQX, a competitive non-NMDA receptor antagonist, decreased EMG activity evoked by AMPA and glutamate. Bold, $p<0.05$ paired Student's $t$ test; bold italic, $p<0.05$, Wilcoxon rank test.

\section{Application of lidocaine to caudal brainstem}

To determine whether the activity evoked by EAA application to the TMJ region was attributable to activation of a reflex pathway as opposed to direct activation of the masseter or digastric muscles, the effect of applying lidocaine $1 \%$ solution or normal saline to caudal brainstem was examined. Application of lidocaine $(2 \mu \mathrm{l})$ to a region $1 \mathrm{~mm}$ lateral of the midline and $4 \mathrm{~mm}$ caudal to the obex (i.e., caudal subnucleus caudalis; Hu et al., 1997), reversibly suppressed glutamate-evoked activity in both jaw muscles (Fig. 7). In contrast, application of normal saline to the brainstem had no effect on jaw muscle activity evoked by glutamate application to the TMJ region.

\section{Evans blue extravasation}

Control experiments using MO confirmed previously reported results indicating that MO causes extensive infiltration of Evans 


\section{Ipsilateral Digastric}

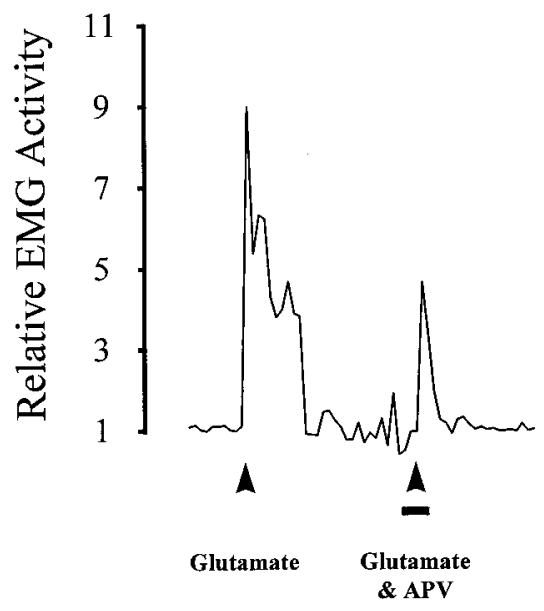

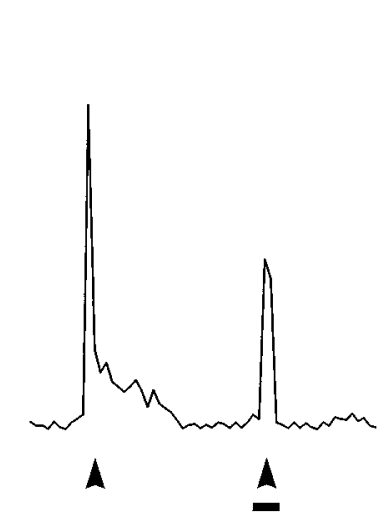

NMDA

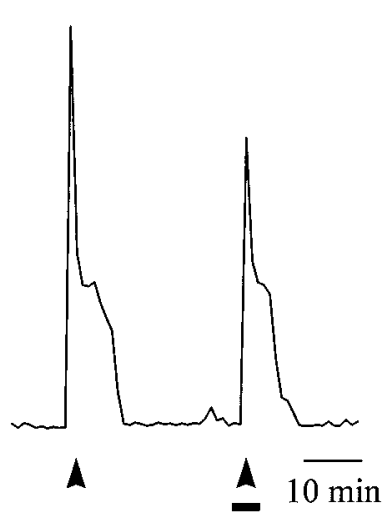

AMPA AMPA

Figure 5. Effect of APV on the activity evoked in the ipsilateral digastric muscle by application of EAA receptor agonists to the TMJ region. Line plots illustrate the activity evoked in the ipsilateral digastric muscle by two applications (solid arrow) each of glutamate $(2.5 \mu \mathrm{mol})$, NMDA (0.5 $\mu$ mol), or AMPA $(0.5 \mu \mathrm{mol})$ in three individual experiments. The first application contained only the indicated EAA receptor agonist, whereas in the second application both the EAA and APV $(0.5 \mu \mathrm{mol}$; solid line $)$ were applied together to the TMJ. Note that co-application of APV reduced the magnitude for glutamate- and NMDA-evoked digastric muscle responses without affecting AMPA-evoked digastric muscle responses, indicating that this dose of APV was selective for NMDA receptors.

\section{Ipsilateral Digastric}
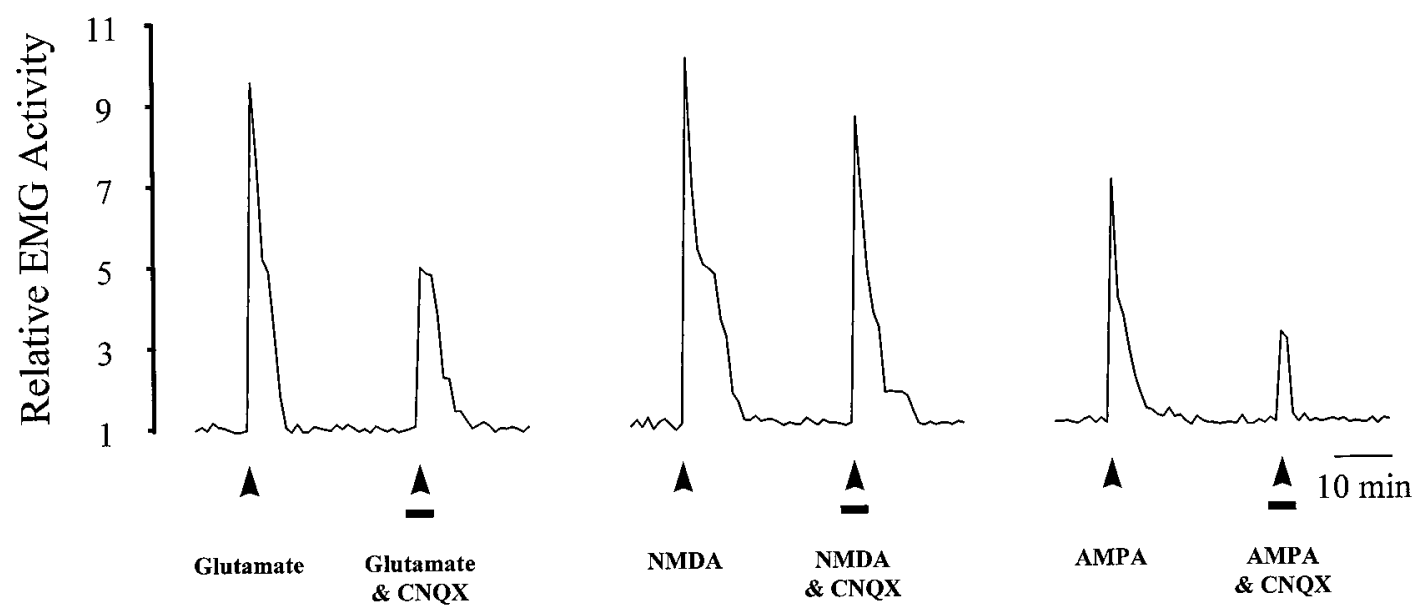

Figure 6. Effect of CNQX (1 nmol; solid line) on the activity evoked in the ipsilateral digastric muscle by application of EAA receptor agonists to the TMJ region. Line plots illustrate the activity evoked in the ipsilateral digastric muscle as described in Figure 5. Note that co-application of CNQX reduced the magnitude for glutamate- and AMPA-evoked digastric muscle responses without affecting NMDA-evoked digastric muscle responses, indicating that this dose of CNQX was selective for non-NMDA receptors.

blue dye into the TMJ region ( $n=4$ rats; Haas et al., 1992; Yu et al., 1995). This measurement indicates extravasation of plasma proteins into the TMJ region. Application of glutamate did not result in visible dye deposition in the TMJ region $(n=8$ rats), which suggests that application of EAA receptor agonists, unlike $\mathrm{MO}$, does not result in significant plasma protein extravasation into the TMJ region.

\section{DISCUSSION}

In the current study, it was discovered that local application of EAA receptor agonists to the TMJ region increased jaw muscle activity and that these EAA-evoked increases in EMG activity were attenuated by co-application of doses of selective EAA receptor antagonists. We have interpreted these results to suggest that both NMDA and non-NMDA EAA receptors are located 


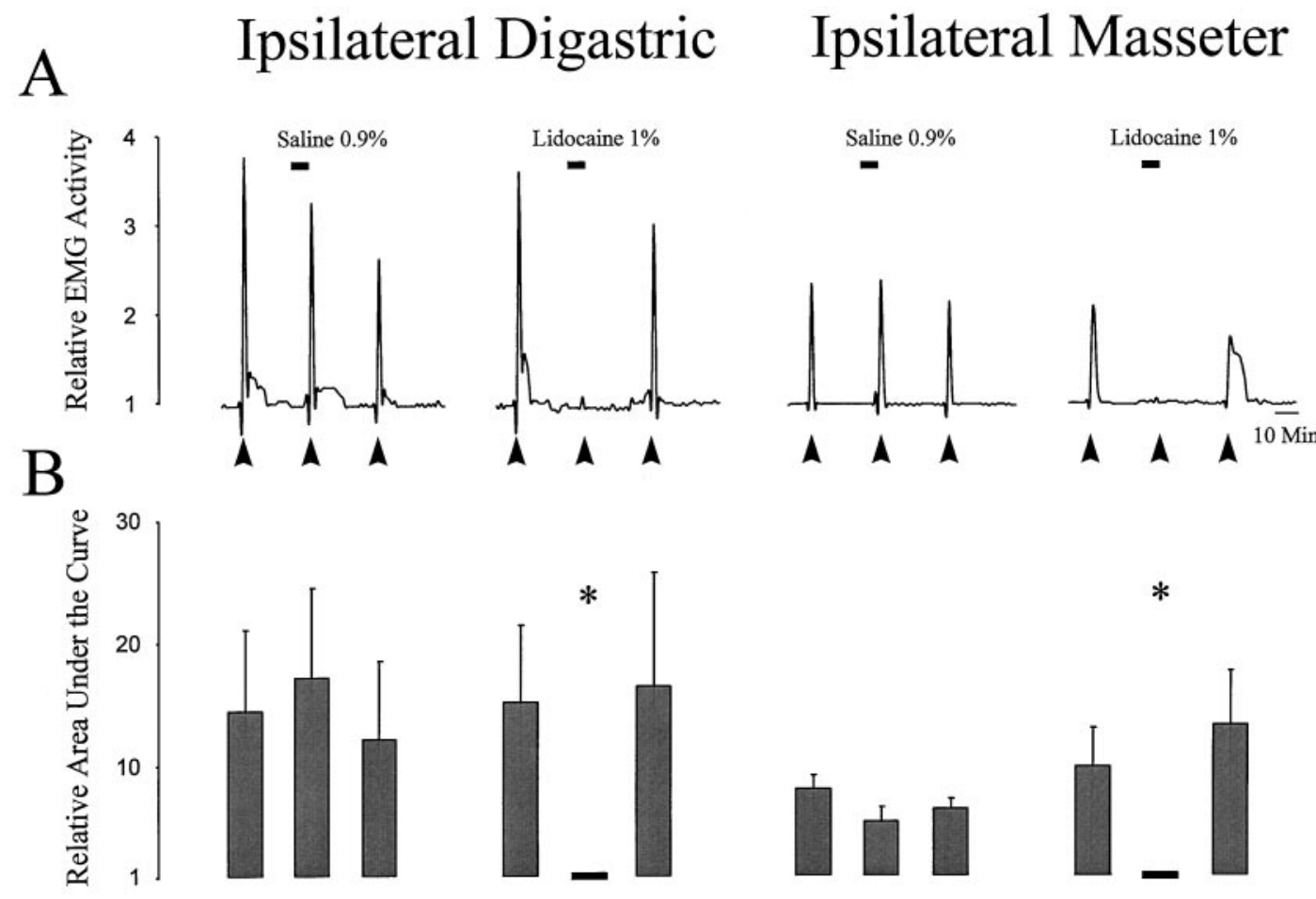

Figure 7. Effect of application of lidocaine to the subnucleus caudalis on the activity evoked in the ipsilateral jaw muscles by application of glutamate to the TMJ region. Line plots in $A$ illustrate the activity evoked in the ipsilateral digastric and masseter muscles by three applications (solid arrow) of glutamate $(2.5 \mu \mathrm{mol})$ to the TMJ region from two individual experiments. The second application of glutamate to the TMJ region was preceded by application of either normal saline or lidocaine over the subnucleus caudalis (solid line). Bar graphs indicate the mean \pm SE $(n=5)$ for each application. Note that application of lidocaine, but not normal saline, to the brainstem reversibly blocked glutamate-evoked activity in the ipsilateral digastric and masseter muscles (asterisk, $p<0.05$, Student's $t$ test). This result indicates that application of glutamate to the TMJ region evokes activity in the jaw muscles by a reflex pathway through subnucleus caudalis.

within the TMJ region and may contribute to the jaw muscle activity that can be reflexively evoked from this region.

\section{Technical limitations}

Access to the rat TMJ is restricted by both its small size and its partial obstruction by the zygomatic arch. As a result, it was necessary to apply drug solutions of a fixed volume to a single point within the joint region. A disadvantage of this mode of drug administration is that it does not allow an assessment of the resulting concentration of the EAA agonists within the TMJ region. In addition, application of hypertonic solutions of EAA receptor agonists, e.g., concentrations greater than $\sim 1 \mu \mathrm{mol} / 10$ $\mu \mathrm{l}$, may also evoke jaw muscle activity, in part because of their osmolar strength (Broton and Sessle, 1988).

The masseter muscle overlies the TMJ region, and it is possible that application of EAA agonists to the TMJ region might activate this muscle directly. Local application of lidocaine to the rat TMJ region (Yu et al., 1995) and surgical or ibotenic acid lesions of the trigeminal subnucleus caudalis (Tsai et al., 1996; Hu et al., 1997) suppress MO-evoked jaw muscle activity, which suggests that a reflex pathway is involved. In the present report, it was found that application of lidocaine to the trigeminal subnucleus caudalis also resulted in a reversible suppression of glutamateevoked EMG activity in both the digastric and masseter muscles. Taken together, these results indicate that application of MO or glutamate to the TMJ region activates a reflex pathway.

There is a considerable interanimal variability in the magnitude of jaw muscle activity evoked by application of both MO and EAAs to the TMJ region. Many factors may account for this variability, e.g., slight differences in the depth of anesthesia, surgical preparation, placement of the TMJ catheter needle tip, initial EMG activity, and even differences in the density of EAA receptors within the TMJ region. This variability, in particular, limits interpretation of the EAA dose-response curve to an indication of minimally and maximally effective doses only. Nonetheless, our finding that jaw reflex activity within the same animal is relatively reproducible with repeated applications of the same dose of glutamate, NMDA, and AMPA indicates that variability was not a major issue in this study.

\section{The potential role of glutamate in peripheral mechanisms of nociception}

We have previously reported that application of the inflammatory irritant and small-fiber excitant MO to the rat TMJ region results in a characteristic increase in the EMG activity of both the digastric (jaw opener) and masseter (jaw closer) muscles bilaterally (Yu et al., 1994, 1995, 1996; Hu et al., 1997; Bakke et al., 1998). Algesic chemical stimulation of the cat TMJ region also evokes jaw muscle activity (Broton and Sessle, 1988). The present report indicates that application of EAA receptor agonists to the rat TMJ region evokes a similar co-activation of these jaw muscles, and thus it is possible that EAA receptor agonists may activate the same putative nociceptive reflex pathways as MO and other algesic chemicals (see $\mathrm{Hu}$ et al., 1997).

It has been previously reported that glutamate and kainate application to the tail skin can evoke a putative nociceptive reflex in the neonatal rat isolated spinal cord-tail preparation (Ault and Hildebrand, 1993a,b). These investigators reported that gluta- 
mate could evoke ventral root reflexes of a similar magnitude over repeated trials by activating a peripheral non-NMDA receptor. Although these findings are consistent with our data, we found that equimolar doses of NMDA, AMPA, or kainate applied to the TMJ region were effective in evoking jaw muscle activity, whereas NMDA and AMPA did not evoke ventral root reflexes when applied to the rat tail skin (Ault and Hildebrand, 1993a,b). This difference may have resulted from the use of neonatal as opposed to adult rats for the isolated spinal cord-tail model or could reflect differences between cutaneous versus deep tissues.

A number of studies have also provided indirect evidence in support of a role for peripheral glutamate receptors in the transduction of nociceptive information. In rats, the development of thermal and/or mechanical hyperalgesia observed after intraplantar or intrarticular (knee and TMJ) application of irritant chemicals can be mimicked by application of EAA receptor agonists to these sites (Yu et al., 1996; Zhou et al., 1996; Davidson et al., 1997; Lawand et al., 1997). Moreover, it has been reported that peripheral application of selective EAA receptor antagonists may attenuate behavioral signs of irritant chemical-induced hyperalgesia (Jackson et al., 1995; Davidson et al., 1997; Lawand et al., 1997).

\section{Peripheral neural mechanisms underlying the reflex activation of jaw muscles}

The mechanisms underlying the MO or EAA receptor agonistevoked activation of TMJ afferents remain unclear. However, our present results, along with our earlier data that local application to the TMJ region of the NMDA antagonist MK 801 blocks MO-evoked jaw muscle activity (Yu et al., 1996), indicate that peripheral EAA receptors appear to play a role in mediating both glutamate- and MO-evoked increases in jaw muscle activity. This suggests that application of MO may cause levels of glutamate to increase sufficiently to activate peripheral EAA receptors located within the TMJ region.

It has been demonstrated that application of the inflammatory irritant $\mathrm{MO}$ to the TMJ region results in significant plasma extravasation (Haas et al., 1992; Yu et al., 1995, 1996). Plasma extravasation can occur within a few seconds after a noxious stimulus is applied (Raab 1992). The concentration of glutamate in plasma is $\sim 300 \mu \mathrm{M}$, which is greater than the reported $\mathrm{ED}_{50}$ for activation of peripheral glutamate receptors (Ault and Hildebrand, 1993a,b; Erdo, 1991). Therefore, plasma extravasation into the TMJ region could be predicted to rapidly elevate glutamate concentrations to a level that could activate EAA receptors located within the TMJ region.

It is also possible that glutamate and excitatory neuropeptides may be released from the peripheral endings of trigeminal afferents as a result of chemical injury to the TMJ region. Glutamate is present in and released from the central terminals of smalldiameter spinal cord and trigeminal afferents, including TMJ afferents, but it is not known whether glutamate is also released from the peripheral endings of trigeminal afferent fibers (Salt and Hill, 1983; Wanaka et al., 1987; Battaglia and Rustioni, 1988; Kai-Kai, 1989; Westlund et al., 1989; Clements and Beitz 1991; Clements et al., 1991; Kai-Kai and Howe, 1991; Azerad et al., 1992; Boucher et al., 1993; Bereiter and Benetti, 1996). Depolarization of trigeminal afferents does, however, result in the peripheral release of neuropeptides such as substance $\mathrm{P}$ and calcitonin gene-related peptide (CGRP) (Jackson and Hargreaves, 1997; Sahara et al., 1997). Small-diameter fibers that exhibit CGRP immunoreactivity have been located within the TMJ region, and the levels of both substance P and CGRP increase after the induction of arthritis in the rat TMJ (Ichikawa et al., 1990; Lundeberg et al., 1996). Thus the neurogenic release of, for example substance P and CGRP, may contribute to the magnitude and duration of the reflex activity in the jaw muscles that we have documented with application of EAA receptor agonists or MO to the TMJ region.

\section{The role of EAA receptors in inflammation}

In addition to activating reflex jaw muscle activity, application of $\mathrm{MO}$, but not glutamate, to the TMJ region also results in significant inflammation, as measured by the Evans blue plasma extravasation method (Haas et al., 1992; Yu et al., 1995, 1996). Our results are in agreement with a report that local application of EAA receptor agonists does not inflame either the knee joint or glabrous skin (Coggeshall et al., 1997; Lawand et al., 1997). Taken together, these results support the concept that changes in peripheral afferent excitability after the application of glutamate are not produced indirectly as a result of inflammation.

Pain in the face and mouth is particularly disturbing, and temporomandibular disorders (TMDs), which may afflict the sufferer with a painful TMJ and/or jaw muscles as well as disturbances in jaw movements, are a significant source of pain complaints (Lund and Sessle, 1994; Sessle, 1995; Stohler, 1995). However, common pharmacological approaches to the treatment of TMD-related pain may be limited by undesirable side effects (Dionne, 1995). The identification of peripheral EAA receptors within the TMJ region may provide a basis for the development of novel therapeutic agents for the treatment of TMD-related pain.

\section{REFERENCES}

Agrawal SG, Evans RH (1986) The primary afferent depolarizing action of kainate in the rat. Br J Pharmacol 87:345-355.

Ault B, Hildebrand LM (1993a) Activation of nociceptive reflexes by peripheral kainate receptors. J Phamacol Exp Ther 265:927-932.

Ault B, Hildebrand LM (1993b) L-Glutamate activates peripheral nociceptors. Agents Actions 39:c142-c144.

Azerad J, Boucher Y, Pollin B (1992) Occurrence of glutamate in primary sensory trigeminal neurons innervating the rat dental pulp. C R Acad Sci III 314:469-475.

Bakke M, Hu JW, Sessle BJ (1998) Involvement of NK-1 and NK-2 tachykinin receptor mechanisms in jaw muscle activity reflexly evoked by inflammatory irritant application to the rat temporomandibular joint. Pain 75:219-227.

Battaglia G, Rustioni A (1988) Coexistence of glutamate and substance $\mathrm{P}$ in dorsal root ganglion neurons of the rat and monkey. J Comp Neurol 277:302-312.

Bereiter DA, Benetti AP (1996) Excitatory amino acid release within spinal trigeminal nucleus after mustard oil injection into the temporomandibular joint region of the rat. Pain 67:451-459.

Birch PJ, Grossman CJ, Hayes AG (1989) Antagonism profile of 6,7dichloro-3-hydroxy-2-quinoxalinecarboxylate at excitatory amino acid receptors in the neonatal rat spinal cord. Eur J Pharmacol 156:177-180.

Boucher Y, Pollin B, Azerad J (1993) Microinfusions of excitatory amino acid antagonists into the trigeminal sensory complex antagonize the jaw opening reflex in freely moving rats. Brain Res 614:155-163.

Broton JG, Sessle BJ (1988) Reflex excitation of masticatory muscles induced by algesic chemicals applied to the temporomandibular joint of the cat. Arch Oral Biol 33:741-747.

Cairns BE, Sessle BJ, Hu JW (1997) Local application of glutamate to the rat temporomandibular joint induces increases in jaw muscle activity through activation of peripheral NMDA and non-NMDA receptors. Soc Neurosci Abstr 23:1256.

Carlton SM, Hargett GL, Coggeshall RE (1995) Localization and activation of glutamate receptors in unmyelinated axons of rat glabrous skin. Neurosci Lett 197:25-28.

Clements JR, Beitz AJ (1991) An electron microscopic description of 
glutamate-like immunoreactive axon terminals in the rat principal sensory and spinal trigeminal nuclei. J Comp Neurol 309:271-280.

Clements JR, Magnusson KR, Hautman J, Beitz AJ (1991) Rat tooth pulp projections to spinal trigeminal subnucleus caudalis are glutamatelike immunoreactive. J Comp Neurol 309:281-288.

Coggeshall RE, Zhou S, Carlton SM (1997) Opioid receptors on peripheral sensory axons. Brain Res 764:126-132.

Collingridge GL, Lester RAJ (1989) Excitatory amino acid receptors in the vertebrate central nervous system. Pharmacol Rev 40:143-209.

Davidson EM, Coggeshall RE, Carlton SM (1997) Peripheral NMDA and non-NMDA glutamate receptors contribute to nociceptive behaviors in the rat formalin test. NeuroReport 8:941-946.

Dionne RA (1995) Pharmacologic treatments for temporomandibular disorders. In: Temporomandibular disorders and related pain conditions (Sessle BJ, Bryant PS, Dionne RA, eds), pp 363-374, Seattle: IASP.

Erdo SL (1991) Excitatory amino acid receptors in the mammalian periphery. Trends Pharmacol Sci 12:426-429.

Haas DA, Nakanishi O, MacMillan RE, Jordan RC, Hu JW (1992) Development of an orofacial model of acute inflammation. Arch Oral Biol 37:417-422.

Hablitz JJ, Sutor B (1990) Excitatory postsynaptic potentials in rat neocortical neurons in vitro. II. Effects of a quinoxalinedione non-NMDA receptor antagonist. J Neurophysiol 64:1282-1290.

Hu JW, Yu X-M, Vernon H, Sessle BJ (1993) Excitatory effects on neck and jaw muscle activity of inflammatory irritant applied to cervical paraspinal tissues. Pain 55:243-250.

Hu JW, Tsai C-M, Bakke M, Seo K, Tambeli CH, Vernon H, Bereiter DA, Sessle BJ (1997) Deep craniofacial pain: involvement of trigeminal subnucleus caudalis and its modulation. In: Progress in pain research and management (Jensen TS, Turner JA, Wiesenfeld-Hallin, eds), pp 497-506. Seattle: IASP.

Huettner JE (1990) Glutamate receptor channels in rat DRG neuron activation by kainate and quisqualate and blockade of desensitization by Con A. Neuron 5:255-266.

Ichikawa H, Matsuo S, Wakisaka S, Akai M (1990) Fine structure of calcitonin gene-related fibres in the rat temporomandibular joint. Arch Oral Biol 35:727-30.

Jackson DL, Hargreaves KM (1997) Evaluations of AMPA-evoked iCGRP release in bovine dental pulp. Soc Neurosci Abstr 27:1535.

Jackson DL, Graff CB, Richardson JD, Hargreaves KM (1995) Glutamate participates in the peripheral modulation of thermal hyperalgesia in rats. Eur J Pharmacol 284:321-325.

Kai-Kai MA (1989) Cytochemistry of the trigeminal and dorsal root ganglia and spinal cord of the rat. Comp Biochem Physiol 93A:183-193.

Kai-Kai MA, Howe R (1991) Glutamate-immunoreactivity in the trigeminal and dorsal root ganglia, and intraspinal neurons and fibres in the doral horn of the rat. Histochem J 23:171-179.

Lawand NB, Willis WD, Westlund KN (1997) Excitatory amino acid receptor involvement in peripheral nociceptive transmission in rats. Eur J Pharmacol 324:169-177.

Lund JP, Sessle BJ (1994) Neurophysiological mechanisms related to chronic pain disorders of the temporomandibular joint and masticatory muscles. In: Temporomandibular joint and masticatory muscle disorders (Zarb G, Carlsson G, Sessle B, Mohl N, eds), pp 187-207, Copenhagen: Munksgaard.
Lundeberg T, Alstergren P, Appelgren A, Appelgren B, Carleson J, Kopp S, Theodorsson E (1996) A model for experimentally induced temporomandibular joint arthritis in rats: effects of carrageenan on neuropeptide-like immunoreactivity. Neuropeptides 30:37-41.

Pelkey KM, Marshall, KC (1995) Responsiveness of mesencephalic trigeminal nucleus neurons to excitatory amino acids. Soc Neurosci Abstr 21:1163.

Raab W H-M (1992) Temperature related changes in pulpal microcirculation. Proc Finn Dent Soc 88:469-479.

Sahara Y, Noro N, Iida Y, Soma K, Nakamura Y (1997) Glutamate receptor subunits GluR5 and KA-2 are coexpressed in rat trigeminal ganglion neurons. J Neurosci 17:6611-6625.

Salt TE, Hill RG (1983) Neurotransmitter candidates of somatosensory primary afferent fibres. Neuroscience 10:1083-1103.

Sato K, Kiyama H, Park HT, Tohyama M (1993) AMPA, KA and NMDA receptors are expressed in the rat DRG neurones. NeuroReport 4:1263-1265.

Sessle BJ (1995) Masticatory muscle disorders: basic science perspectives. In: Temporomandibular disorders and related pain conditions (Sessle BJ, Bryant PS, Dionne RA, eds), pp 47-61. Seattle: IASP.

Stohler CS (1995) Clinical perspectives on masticatory and related muscle disorders. In: Temporomandibular disorders and related pain conditions (Sessle BJ, Bryant PS, Dionne RA, eds), pp 3-29. Seattle: IASP.

Tachibana M, Wenthold RJ, Morioka H, Petralia RS (1994) Light and electron microscopic immunocytochemical localization of AMPAselective glutamate receptors in the rat spinal cord. J Comp Neurol 344:43-454.

Tsai C-M, Sessle BJ, Hu JW (1996) Involvement of trigeminal subnucleus caudalis $(\mathrm{Vc})$ in craniofacial nociceptive reflex. In: Abstracts: 8th World Congress of Pain (Sessle BJ, Bryant PS, Dionne RA, eds), pp 231-232. Seattle: IASP.

Wanaka A, Shiotani Y, Kiyama H, Matsuyama T, Kamada T, Shiosaka S, Tohyama M (1987) Glutamate-like immunoreactive structures in primary sensory neurons in the rat detected by a specific antiserum against glutamate. Exp Brain Res 65:691-694.

Westlund KN, McNeill DL, Coggeshall RE (1989) Glutamate immunoreactivity in rat dorsal root axons. Neurosci Lett 96:13-17.

Yamada KA, Dubinsky JM, Rothman SM (1989) Quantitative physiological characterization of a quinoxalinedione non-NMDA receptor antagonist. J Neurosci 9:3230-3236.

Yu X-M, Sessle BJ, Vernon H, Hu JW (1994) Administration of opiate antagonist naloxone induces recurrence of increased jaw muscle activities related to inflammatory irritant application to rat temporomandibular joint region. J Neurophysiol 72:1430-1433.

Yu X-M, Sessle BJ, Vernon H, Hu JW (1995) Effects of inflammatory irritant application to the rat temporomandibular joint on jaw and neck muscle activity. Pain 60:143-149.

Yu X-M, Sessle BJ, Haas DA, Izzo A, Vernon H, Hu JW (1996) Involvement of NMDA receptor mechanisms in jaw electromyographic activity and plasma extravasation induced by inflammatory irritant application to temporomandibular joint region of rats. Pain 68:169-178.

Zhou S, Bonasera L, Carlton SM (1996) Peripheral administration of NMDA, AMPA or KA results in pain behaviors in rats. NeuroReport 7:895-900. 